\title{
Dermeval Saviani e a centralidade ontológica do trabalho na formação do "homem novo", artífice da sociedade socialista
}

Gaudencio Frigotto ${ }^{(a)}$

Frigotto G. Dermeval Saviani and the ontological centrality of work for building the "new man", maker of the socialist society. Interface (Botucatu). 2017; 21(62):509-19.

This paper states the ontological centrality of work across the research done by Dermeval Saviani, philosopher and educator. The materialist conception of history, the dialectical method of understanding human reality and the meaning of political action are all based, throughout history, on the crucial human activity of work and the way it is defined by social relations of material production of existence conditions through time. Finally, the paper analyzes the exegetical and heuristic view of 'new' critiques of the author's thoughts.

Keywords: Dialectical method. Work. Education. Politics. Heuristic.
O presente texto explicita a centralidade ontológica do trabalho no conjunto da obra do filósofo e educador Dermeval Saviani. A concepção materialista da história, o método dialético de compreensão da realidade humana e o sentido da ação política se fundamentam na atividade vital do trabalho e como este se define nas relações sociais de produção material da existência, ao longo do tempo. Ao fim, analisa-se a visão exegética e heurística de "novas" críticas do pensamento do autor.

Palavras-chave: Método dialético. Trabalho. Educação. Política. Heurística. (a) Faculdade de Educação, Universidade do Estado do Rio de Janeiro. Rua São Francisco Xavier, 524, $12^{\circ}$ andar, Maracanã. Rio de Janeiro, RJ, Brasil, 24210-350. gfrigotto@globo.com 
"Os filósofos se limitaram a interpretar o mundo de diferentes maneiras; o que importa é transformá-lo". ${ }^{1}$ (p. 118)

\section{Introdução}

Os leitores que têm uma visão da ampla e densa obra de produção científica de Dermeval Saviani, sem dúvida o filósofo e intelectual marxista mais importante do campo educacional no Brasil, podem estranhar a escolha do título deste texto. Com efeito, Saviani, a não ser em alguns textos específicos, não se ocupa diretamente do tema do trabalho. Então, como poderia ser esta a categoria central no conjunto de sua obra?

$\mathrm{Na}$ brevidade deste texto, buscarei responder a essa questão, destacando que a dimensão ontológica do trabalho, de forma explícita e implícita, constitui-se no pressuposto de toda a obra de Saviani, tanto no plano de sua opção epistemológica quanto no âmbito de sua ação política na luta pelo socialismo ${ }^{(b)}$. Como nota final, farei uma breve menção sobre o caráter abstrato e lógico-dedutivo de alguns dos seus críticos em relação à questão do trabalho e do trabalho como princípio educativo.

\section{O pressuposto do trabalho na concepção teórica e política no conjunto da obra de Dermeval Saviani}

A centralidade do trabalho em sua dimensão ontocriativa constitui-se como pressuposto ao longo da obra de Dermeval Saviani por ser este a atividade vital que define a especificidade do ser humano e, como tal, ponto de partida e de chegada da análise que se inscreve em uma perspectiva materialista histórica. Vale dizer que, em Marx², somente é histórica a análise que busca compreender as formas concretas de os seres humanos produzirem sua existência em relações com outros seres humanos ao longo dos tempos. "Por isso, o trabalho - processo entre o homem e a natureza, um processo que o homem, por sua própria ação, medeia, regula e controla seu metabolismo com a natureza" (p.149) - é uma categoria antidiluviana.

Nesse sentido, a concepção materialista histórica é, ao mesmo tempo, uma concepção de como se produz a realidade humana em todas as suas dimensões, um método dialético na apreensão de como essa realidade se produz sob as relações classistas no seio do modo de produção capitalista e uma prática política ou práxis na tarefa de sua superação na construção de uma sociedade sem a exploração de classe, uma humanidade emancipada.

No texto "A relação trabalho e educação: fundamentos ontológicos e históricos" (2007), Saviani ${ }^{3}$ trata sistematicamente do sentido ontológico do trabalho e das formas históricas que assume a relação trabalho e educação e inicia com uma observação que demarca sua visão materialista da realidade humana:

A primeira observação que me ocorre a propósito do próprio enunciado do tema é que, na verdade, da perspectiva em que me coloco para analisar o problema, os termos "ontológico" e "histórico" não seriam ligados por uma conjunção coordenativa aditiva como está posto no enunciado do título. Não se trataria de examinar os fundamentos ontológicos e depois, em acréscimo, examinar os fundamentos históricos, ou vice-versa. Isso porque o ser do homem e, portanto, o ser do trabalho, é histórico. (p. 152)

(b) No espaço deste texto não tenho a pretensão de dissecar a obra extensa e profunda de Dermeval Saviani, mas sim mostrar como a dimensão ontológica do trabalho é o pressuposto que a perpassa, pelo simples fato de que sua abordagem se inscreve na concepção materialista histórica, cujo fundamento é o trabalho. 
(c) $\mathrm{Na}$ continuidade dessa frase, Saviani insere a citação clássica de Marx e Engels, que afirmam a especificidade histórica do ser humano: "Podemos distinguir o homem dos animais pela consciência, pela religião ou por qualquer coisa que se queira. Porém, o homem se diferencia propriamente dos animais a partir do momento em que começa a produzir seus meios de vida, passo este que se encontra condicionado por sua organização corporal. Ao produzir seus meios de vida, o homem produz indiretamente sua própria vida material" ${ }^{4}$ (p. 19, destaque do autor)
Essa não separação real do ontológico e do histórico é demonstrada em seguida, mediante a superação que Marx ${ }^{2}$ faz das concepções metafísicas, idealistas e racionalistas do que define a "essência" do ser humano.

Voltando-nos para o processo de surgimento do homem vamos constatar seu início no momento em que determinado ser natural se destaca da natureza e é obrigado, para existir, a produzir sua própria vida. Assim, diferentemente dos animais, que se adaptam à natureza, os homens têm de adaptar a natureza a si. Agindo sobre ela e transformando-a, os homens ajustam a natureza às suas necessidades ${ }^{(c)}$. [...] ora, o ato de agir sobre a natureza transformando-a em função das necessidades humanas é o que conhecemos com o nome de trabalho. Podemos, pois, dizer que a essência do homem é o trabalho. A essência humana não é, então, dada ao homem; não é uma dádiva divina ou natural; não é algo que precede a existência do homem. Ao contrário, a essência humana é produzida pelos próprios homens. $\mathrm{O}$ que o homem é, é-o pelo trabalho. A essência do homem é um feito humano. É um trabalho que se desenvolve, se aprofunda e se complexifica ao longo do tempo: é um processo histórico. (p. 154, destaque nosso)

Como sublinha Saviani, o ser humano, ao se construir humano pelo trabalho, educa-se em sentido amplo e, na processualidade histórica e no seio das relações sociais de produção capitalistas, de forma contraditória e sempre em disputa, cria espaços específicos de produção e sistematização de conhecimentos científicos que se vinculam à produção e reprodução da "vida".

É nessa compreensão de processualidade histórica que Saviani evidencia o momento de unidade entre trabalho e educação, a necessidade, sob as relações sociais capitalistas de produção, da sua separação e as condições contraditórias desse sistema, que na atualidade implicam, sob outras bases, novamente a unidade. O conhecimento, sob a atual "revolução tecnológica", constitui-se em força produtiva por excelência.

Sob o domínio do capital, o trabalho é dominantemente meio de potenciar os processos de exploração e de alienação. Livre dessa relação de classe, todavia, a ciência e as técnicas que dela derivam constituem-se em meios de diminuição do tempo de trabalho imperativamente dedicado à esfera da necessidade e de ampliação do tempo livre, tempo de efetiva liberdade, de escolha e de fruição, em que as qualidades humanas podem se expandir. Por isso que, para Marx, a ciência e a técnica somente serão forças que dilatarão efetivamente o tempo livre quando libertas de sua subordinação à ampliação do capital. Mesmo sob as relações classistas, entretanto, nem o trabalho, nem a ciência e a técnica são pura negatividade. Situam-se no plano contraditório da realidade historicamente dada, terreno no qual se efetiva a luta de classe. Podemos afirmar que Saviani segue com rigor teórico aquilo que Engels 5 sintetizou como sendo o legado fundamental de Marx:

Assim como Darwin descobriu a lei do desenvolvimento da natureza orgânica, Marx descobriu a lei do desenvolvimento da história humana: o fato, tão simples, mas oculto sob uma manta ideológica, de que o homem necessita, em primeiro lugar, de comer, beber, ter um teto e vestir-se antes de poder fazer política, ciência, arte, religião etc.; de que, portanto, a produção dos meios de vida imediatos, materiais, e, por conseguinte, o grau de desenvolvimento econômico objetivo de um povo 
dado ou durante uma época dada forma a base sob a qual as instituições estatais, as concepções jurídicas, a arte e inclusive as ideias sobre religião do povo em questão têm se desenvolvido, e à luz das quais devem, por tanto, ser explicadas, em vez do contrário, como havia sido o caso até então. (p. 1)

Em seguida, Engel ${ }^{5}$ completa dizendo que: "Marx também descobriu a lei especial do movimento que governa o atual modo capitalista de produção, e a sociedade burguesa que este modo de produção tem criado - a mais-valia." (p. 1).

É por essa base da lei do desenvolvimento da história humana que a obra de Saviani expõe, no plano epistemológico e político, sua concepção de educação em sentido amplo e, em particular, da educação na sua forma escolar. Essas abordagens têm, de forma implícita ou explícita, as dimensões de processualidade, mediação, contradição e particularidade nas relações que os seres humanos estabelecem na produção da sua existência.

$\mathrm{Na}$ elaboração de sua pedagogia histórico-crítica, Saviani analisa as concepções idealistas, racionalistas e pragmáticas de educação e as define como abordagens a-históricas, isto é, que não apreendem a educação no seio das relações sociais capitalistas, marcadas pela cisão e antagonismo de classe. Em seguida, situa as abordagens que concebem a educação como instrumento unilateral de reprodução das relações sociais capitalistas de produção e denomina-as de crítico-reprodutivistas. Críticas porque percebem, sem dúvida, a forma dominante do sistema capital de subordinar o conjunto das relações e práticas sociais, incluindo a educação, no movimento de sua reprodução. Reprodutivistas, contudo, pelo fato de não perceberem, por um lado, o caráter contraditório das relações sociais capitalistas e, por outro, sob essas contradições, a luta de classes.

Essa dupla visão crítica e os elementos de sua superação somente foram possíveis pelo fato de Saviani pautar-se na concepção materialista da história, cujo fundamento é o trabalho. Essa concepção aparece de forma explícita em análise de temas mais pontuais, sempre referidos pelo autor em suas análises mais aprofundadas. Destaco, aqui, apenas dois exemplos do livro "Educação em diálogo"6, no qual estão reunidos 35 textos de entrevistas que o autor concedeu sobre diferentes temas do debate educacional contemporâneo.

$\mathrm{Na}$ entrevista sobre educação e informática, o entrevistador pergunta sobre o impacto das novas tecnologias na relação dos professores com os alunos no processo de ensino. Após situar, como ele mesmo sublinha, um tanto jocosamente, a geração a que pertence como sendo a do "penso, logo existo" e a geração atual, sob o signo da pós-modernidade, a do "digito, logo existo", destaca o que está subjacente e o que é necessário desvelar para não cair no fetiche do determinismo tecnológico.

Assim penso que o principal desafio posto pela interferência digital na educação reside na compreensão do significado histórico-social dos processos de informatização. Entendo que, mais do que familiarizar os alunos com os procedimentos de digitação, o papel da educação escolar é permitir-lhes a compreensão dos princípios científicos que fundamentam estes procedimentos. [...] é preciso levar em conta que as tecnologias não são outra coisa senão recursos cuja função é auxiliar o trabalho humano, facilitá-lo e maximizar seus efeitos. A base disso é o modo de ser do trabalho humano que consiste numa atividade adequada a finalidades ${ }^{6}$. (p. 143)

Saviani não nega o papel das novas tecnologias no processo pedagógico, mas situa-as como meio na relação entre os professores e os alunos e não como um ente autômato em si e por si criadores de conhecimento. A capacidade exponencial de gerar informações, imagens e dados pelas novas tecnologias não é sinônimo de conhecimento, por isso as novas tecnologias não substituem o professor na sua função fundamental de ajudar os alunos a construírem as bases científicas que lhes podem permitir entender não apenas como se efetivam atualmente os processos produtivos, mas também que, sob o domínio das relações sociais capitalistas, as novas tecnologias são dominantemente meios que aumentam a exploração da classe trabalhadora.

O segundo exemplo é também de outra entrevista, esta sobre educação e transformação social. De imediato, observa-se que, ao mesmo tempo em que a educação não se separa da atividade vital 
do trabalho na produção da existência, tem uma função específica como prática social. Trata-se de uma unidade do diverso. Pode-se apreender essa unidade do diverso na resposta a duas passagens da entrevista sobre a função da educação na produção do ser humano e na transformação da sociedade:

Historicamente a educação se põe como atividade inerente ao próprio processo de hominização, isto é, o processo pelo qual o homem cria a si mesmo ao produzir os meios que Ihe garantem a existência. Por isso a origem da educação coincide com a origem do próprio homem. Ou seja, o homem não nasce homem. [...] Por isso que no livro Pedagogia HistóricoCrítica defini a educação como o ato de produzir, em cada indivíduo singular, a humanidade que é produzida histórica e coletivamente pelo conjunto dos homens. (p. 217)

Note-se que o ato de se educar está implicado no ato de o ser humano criar a si mesmo pelo trabalho, ao produzir os meios de reprodução da sua vida como um ser da natureza, que dela se diferencia pela capacidade de conceber, idear e modificar os instrumentos e meios de sua produção e reprodução. Se trabalho e educação, porém, formam uma unidade indissolúvel, na prática social concreta a educação assume uma especificidade.

Como defini em Escola e democracia, a educação é uma prática social mediadora no interior da prática social global. Portanto, seu influxo transformador se exerce na forma de mediação, isto é, de forma indireta e mediata e não de forma direta e imediata. Seu papel diz respeito a prover as condições subjetivas do processo de transformação que, entretanto, só podem ter eficácia em articulação com as condições objetivas. Eis porque, quando guiado pelo objetivo da transformação social, o educador crítico deve estar atento às condições objetivas, desenvolvendo os instrumentos de compreensão dessas condições e assegurando aos educandos a sua assimilação, o que implica não abrir mão do cumprimento da função específica da escola que se liga ao domínio do saber sistematizado7. (p. 218, destaque nosso)

É por meio da compreensão da unidade diversa entre trabalho e educação e de suas especificidades que Saviani analisa o trabalho como princípio educativo e desenvolve a concepção de educação politécnica. O trabalho como princípio educativo, tanto no sentido amplo de formação humana quanto da escola unitária, situa-se, pois, na compreensão da relação intrínseca entre trabalho humano e educação. O primeiro é ligado imediata e diretamente às "condições objetivas" e necessárias na produção da vida humana, e a segunda é associada de forma indireta e mediata no desenvolvimento das "condições subjetivas".

Saviani, ao tratar do conceito de politecnia, em "Sobre a concepção de politecnia" 8 e em "O choque teórico da politecnia"9 a partir da elaboração de Marx e da tradição socialista, contrapõese à divisão do trabalho manual e intelectual, à separação da concepção e execução no processo de produção e à consequente dualidade na educação e da formação fragmentária e adestradora da classe trabalhadora do projeto societário capitalista. Trata-se de uma concepção que se situa na dialética velho e novo: "Estamos, pois, num contexto em que, como dizia Gramsci, trava-se de uma luta entre o novo que quer nascer e o velho que não quer sair de cena." ${ }^{9}$ (p. 149).

Desse modo, a formação politécnica, "[...] entendida como o desenvolvimento dos fundamentos científicos das diferentes técnicas que caracterizam o processo produtivo do trabalho moderno [...]"8 (p. 17), busca construir "bases subjetivas" que permitam a crítica à forma que assume o trabalho, a ciência, a educação, a cultura e a arte sob as relações sociais capitalistas e dentro destas, pois são as condições historicamente existentes que irão dilatar as possibilidades de sua superação.

Do que se expôs até aqui, fica clara a coerência entre a concepção materialista da história e o método materialista histórico-dialético, mediante o qual analisa a relação entre trabalho e educação, sistema de ensino e educação no processo de superação das relações sociais capitalistas.

Também fica explícito que o autor busca, especialmente em Marx, Engels, Lenin e Gramsci, o sentido da historicidade do real e da processualidade contraditória como marca inerente à forma capital de relações sociais. Em cada obra e mesmo em textos mais curtos ou entrevistas, Saviani prima 
por situá-los de maneira que traga os elementos do contexto histórico e das forças sociais em disputa na sociedade e na educação. O autor evidencia uma relação permanente entre o ontológico (sentido dado por Marx), o histórico, o epistemológico e a práxis política.

\section{Da densa produção teórica à militância política na sociedade e na educação}

A epígrafe do texto busca sinalizar que por dois caminhos Saviani traz uma dupla contribuição singular para o campo da ação política ou práxis, na luta pela transformação radical das relações sociais de produção da existência, na sociedade capitalista e na construção do socialismo. Marx não reduz o papel da teoria na luta política. Pelo contrário, como ele mesmo sublinha, quando ela vai à raiz da realidade humana tem força material revolucionária. Todavia, como observa José Barata-Moura ${ }^{10}$, "Em Marx o pensar e a teoria em si e por si sós revelam-se de todo incapazes de produzir resultados de transformação material da natureza ou da sociedade. O pensar, com efeito, não é predominantemente determinante em relação ao âmbito do ser" (p. 353, destaque do autor).

No processo histórico, o que altera a realidade é a mudança material resultante da ação prática. Trata-se, pois, de um duplo e inseparável movimento - o de buscar entender o que produz ou o que está subjacente às relações sociais do capitalismo e, ao mesmo tempo, atuar praticamente na busca pela superação dessas relações na construção do socialismo. Nesse duplo movimento de elaboração teórica e de atuação prática, Saviani oferece uma contribuição original e ímpar para campo da educação.

A primeira contribuição efetiva-se pela densidade teórica na análise da relação entre educação e sociedade, sem a qual a luta política não tem direção; e a segunda, pelo sistemático embate na crítica das leis e políticas educacionais, ao longo das últimas quatro décadas no Brasil, e pelo seu vínculo orgânico com organizações científicas, políticas e movimentos sociais empenhados na transformação da sociedade e da educação.

Saviani, ao tratar da relação entre educação e democracia, pela base teórica apontada, traz-nos o sentido de como a escola, na produção e socialização do conhecimento, em seu conteúdo, método e forma de educar, exerce a função política de mascarar as relações sociais de exploração ou, no espaço contraditório em que se move a luta de classe, de revelar essas relações e a necessidade de sua superação. Em outras palavras, a concepção, o método de conhecer e seu resultado engendram uma dimensão política e, como tal, não são neutros.

Essa compreensão é sintetizada nas "Onze teses sobre educação e política" (2008), nas quais mostra que educação e política se relacionam dentro de uma unidade diversa. Vale dizer que não estão separadas, mas também não se identificam. "Entendo que educação e política, embora inseparáveis, não são idênticas. Trata-se de práticas distintas, dotadas cada uma de especificidade própria."11 (p. 66).

A exposição de cada tese com um breve corolário busca elucidar a inseparabilidade de ambas, sem diluir sua especificidade. Aqui destacam-se apenas as duas que explicitam esta relação: "Tese 2: Toda prática educativa contém inevitavelmente uma dimensão política" e "Tese 3: Toda prática política contém, por sua vez, inevitavelmente uma dimensão educativa"11 (p. 71).

Esses temas situam-se em um contexto específico do debate teórico e político da educação no Brasil, como Saviani ${ }^{11}$ destaca antes de expor as teses:

De uns tempos para cá se tornou lugar-comum a afirmação de que a educação é sempre um ato político. Mas o que significa essa afirmação? Obviamente, trata-se de um "slogan" que tinha por objetivo combater a ideia anteriormente dominante segundo a qual a educação era entendida como um fenômeno estritamente técnico-pedagógico, portanto, inteiramente autônomo e independente da questão política. (p. 65)

Tais temas ganham outra dimensão e relevância, atualmente, no contexto de uma crescente escalada que segue na direção de anular a função docente de ensinar e de educar, pelo que, como e para que se ensina. O epílogo dessa escalada é a manifestação ultraconservadora da tese "Escola sem Partido", pelo que manifesta e muito mais pelo que esconde. 
(d) Ver, por exemplo, o debate com Paolo Nosella sobre o termo mais adequado em Marx: "educação politécnica" ou "tecnológica em Marx" 3 .
Sublinha-se que a análise que Saviani realiza sobre a relação entre educação e política ajuda a desvelar o que a "Escola sem Partido" efetivamente esconde. No chão da escola, a esfinge da "Escola sem Partido" e da "Liberdade para Ensinar" quebra o que define a relação pedagógica e educativa: uma relação de confiança e de solidariedade. Além disso, trata-se de obrigar os docentes a ensinar e adestrar pelo que reza a cartilha dos "especialistas" e institutos privados autorizados pelo partido do mercado e do capital e a sua metafísica cínica de neutralidade.

A segunda contribuição é a de que o esforço teórico de apreender pela raiz como se produz a realidade humana no seu conjunto, imprescindível para uma ação política não idealista ou voluntarista, não é da mesma natureza da ação política. Esta se inscreve, na sociedade capitalista, no âmbito da luta antagônica e em condições inicialmente não escolhidas.

Aqui, com base em Marx, que não separa a tríade trabalho, capital e Estado, Saviani notabiliza-se por uma análise crítica sistemática das reformas educacionais, dos planos nacionais de educação, da legislação, do Plano de Desenvolvimento da Educação e das Conferências Nacionais de Educação. Podese afirmar que nenhum dos temas mais candentes da disputa pelo sentido da educação escolar no Brasil, nas últimas quatro décadas, escapou à análise e ao posicionamento político de Saviani na perspectiva da luta de classe.

\section{Nota sobre a natureza das críticas à concepção do trabalho como princípio educativo em Saviani}

Por certo, nenhum autor é imune a críticas a sua obra e, assim, Saviani não seria uma exceção. Quem conhece sua obra e sua forma de se conduzir no debate constata que o intelectual tem dialogado com as críticas, analisando-as e incorporado elementos delas ${ }^{(d)}$.

No texto sobre polissemia da categoria trabalho, pelo fato de Lessa ${ }^{12}$ e Tumolo ${ }^{13}$ ligarem a minha análise e a de outros autores à abordagem de Dermeval Saviani, estabeleci um breve debate com estes, distinguindo inclusive o teor e a densidade da análise de Lessa e de Tumolo ${ }^{14}$.

Sublinhei naquele texto a discussão de Thompson sobre conceito de classe social e como historiadores trabalham os mesmos conceitos com significados diferentes: uns buscam apreendê-los na processualidade histórica e outros efetivam a análise heurística e analítica, sendo todos legítimos. Thompson, citado por Negro e Silva ${ }^{15}$, adverte: "Todavia, confusões geralmente surgem quando nos deslocamos de uma acepção para outra." (p. 1). Por que voltar, então, ao tema e especificamente em relação a Tumolo? Faço isso, apenas como registro, por três razões.

Primeiro porque Tumolo ${ }^{16}$ repete, de forma requintada e ampliada, as mesmas críticas, mesmo depois de ter conhecimento da elegante e incisiva reposta à tese de seu orientando Ademir Lazarini ${ }^{17}$, na qual Saviani e Duarte ${ }^{18}$ sinalizam que: " [...] a referida tese não traz novidade, pois retoma os mesmos argumentos de Sérgio Lessa, Ivo Tonet e Paulo Sérgio Tumolo [...]." (p. 122). E, logo adiante, acrescenta:

A não ser o fato de reunir num só trabalho um conjunto de críticas formuladas de forma mais ou menos esparsas, além do caráter bombástico com que as denúncias são apresentadas, como já se pode ver apenas pela leitura do sumário da tese ${ }^{18}$. (p. 122)

Saviani, contudo, reconhece a pertinência de estudos que buscam a exegese ou hermenêutica dos textos no tempo histórico em que foram produzidos, mas explicita que não segue esse caminho. O que busca nos autores clássicos do marxismo é 
como eles podem " [...] nos ajudar a compreender nossa realidade e enfrentar com mais consistência os problemas da educação brasileira [...]."18 (p. 124).

Os textos de Tumolo sobre o tema trabalho e trabalho como princípio educativo situam-se inequivocamente no plano da hermenêutica ou análise heurística ou analítica dos textos de Marx. Até aí, não há objeções, pois a escolha é dele e pode ser fecunda ${ }^{(e)}$. O problema é que insiste no que Edward P. Thompson adverte sobre as confusões do deslocamento da análise heurística, o que para Oliveira ${ }^{19}$ significa " [...] não alcançar-se a saturação histórica do concreto, isto é, não saber apanhar a multiplicidade de determinações que fazem o concreto [...]." (p. 9).

O que sistematicamente faz, nesse "deslocamento", é uma análise silogística nos parâmetros da lógica formal e na perspectiva do raciocínio dicotômico, pois toma trechos muitas vezes fora do contexto do conjunto das análises de Saviani, vai aos textos de Marx e volta a fazer conclusões sobre os equívocos do autor criticado. O estranho é a insistência com os mesmos autores, com os mesmos argumentos, apenas com pequenas alterações. Aqui, tomam-se como exemplo os textos de Tumolo ${ }^{13,16}$.

Tumolo $^{13}$, em um de seus textos, toma um trecho de uma entrevista de Saviani na qual assinala que o sistema escolar se estrutura a partir da questão do trabalho, por ser este a base da existência humana, e justifica que, dado o número de educadores que se ocupam do tema, seleciona apenas este porque "sintetiza a concepção presente no conjunto de seus estudiosos." (p. 241). Em uma nota, a título de exemplo, nomeia 13 educadores, elencando 23 obras supostamente vinculadas à mesma visão.

Em outro texto, 13 anos depois, Tumolo ${ }^{16}$, na primeira página, toma literalmente o mesmo parágrafo de $2003^{13}$ e agora inclui no texto oito autores que tratam da questão do trabalho como princípio educativo, mas em nota de rodapé acrescenta mais cinco, o que redunda em 13 aqui também. A soma das obras agora é de trinta. Nesse caso, o argumento é de que não vai tratar de todos os autores citados dada a sua complexidade e profundidade e, por isso, aborda somente Saviani e Frigotto.

A inovação consiste na menção a uma citação minha para mostrar uma divergência não na concepção de trabalho, mas no fato de que, em Saviani, o princípio educativo do trabalho relaciona-se à escola. Diante disso, eu assinalo: "Da leitura que faço do trabalho como principio educativo em Marx, ele não está ligado diretamente ao método pedagógico ou à escola [...]."16 (apud Tumolo, p. 404). Adiante, ele me cobra de onde tirei isso de Marx.

Tumolo, por não trabalhar na perspectiva da historicidade e, portanto, da dialética da unidade do diverso, não percebe que, se digo "não diretamente", significa que admito que de forma mediata o trata. Quem liga diretamente o trabalho como princípio educativo à escola é Gramsci, do qual Saviani parte; mas Marx trata do princípio educativo do trabalho, em acordo com o que Saviani ${ }^{20}$ expõe: "Historicamente a educação se põe como atividade inerente ao próprio processo de hominização, isto é o processo pelo qual o homem cria a si mesmo ao produzir os meios que lhes garante a existência" (p. 110). É fundamental, portanto, na formação do homem novo e na perspectiva do socialismo, que desde a infância se incorpore na prática o dever ético (por que é da condição universal do ser humano) do trabalho socialmente produtivo e entenda-se que quem não trabalha, explora.

No texto de Tumolo a que agora estou me referindo ${ }^{16}$, há a repetição da mesma lógica de $2003^{13}$, começando com uma citação de cada autor; em seguida, há a reiterada explanação sobre como ele entende em Marx os conceitos em debate e retoma novamente os autores para evidenciar seus equívocos (e) Os trabalhos de Mário A. Manacorda são, nesse sentido, extraordinários e fecundos. 
interpretativos. Com isso, parece estar fazendo escola, com deformações mais sérias em jovens pesquisadores, reivindicando de forma arrogante a verdadeira leitura de Marx e Gramsci, lembrando os debates metafísicos de mesmo teor sobre a verdadeira interpretação da bíblia.

Dessa postura deriva a segunda razão, cujo exemplo emblemático e de ingênua arrogância intelectual é a tese de Lazarini ${ }^{12}$, mas do qual podem vir outras críticas na mesma direção para os outros 12 autores mencionados por Tumolo, que, de acordo com esse autor, por mera suposição, perfilam a mesma linha de Saviani. Vale mencionar o texto de Saviani ${ }^{18}$, no qual desmonta uma a uma as bombásticas afirmações do jovem pesquisador.

Como exemplo do teor bombástico e acusatório, Saviani destaca, entre vários, a crítica que dá título ao item 3.5.2 de tese acima referida ${ }^{17}$ - "Educação como trabalho imaterial: simbiose entre idealismo e empirismo sensitivo". Saviani retoma o capítulo VI (inédito) de Marx para mostrar o ponto em que o filósofo trata literalmente da questão por ele trabalhada e que o doutorando não deve ter lido: "Diante desta constatação, cabe a seguinte ironia: pobre do nosso Marx. Tão limitado intelectualmente que acabou sendo vítima da simbiose entre idealismo e empirismo sensível"18 (p. 135). Em seguida, Saviani desmonta o mesmo equívoco grosseiro sobre a crítica a sua concepção de trabalho como princípio educativo, entretanto, aqui o limitado intelectualmente passa a ser Gramsci. Mais adiante, Saviani desmonta os quatro argumentos pelos quais é acusado de se afastar do marxismo.

O que é mais preocupante, e isso se liga à ultima razão dessa nota, é o que Saviani ${ }^{18}$ relata na primeira parte do seu texto: Lazarini nunca o procurou durante a produção da tese. Saviani corretamente observa que quando o autor está vivo e deseja-se analisar sua obra, é usual e metodologicamente importante consultálo. Saviani, entretanto, foi convidado para uma mesa do V Encontro Brasileiro de Educação e Marxismo para ouvir seu jovem crítico. Saviani ${ }^{18}$, com total razão, afirma:

Da forma como aconteceu, não fui tratado como um companheiro do mesmo campo teórico-político-ideológico a quem se endereçam críticas para fazê-lo avançar ou para corrigir desvios detectados em sua apropriação da teoria, no caso, o marxismo. De fato, fui tratado como um inimigo a abater. (p. 123, destaque nosso)

A questão aqui é dupla. Primeiro, a quem serve essa "forma da crítica",

(f) Quero crer que os organizadores da coletânea não tinham conhecimento da natureza e antecedentes do debate, cujo teor das críticas, na linha do que indica Saviani, é menos de ajudar colegas do mesmo campo teóricopolítico-ideológico do marxismo para avançar e mais uma estratégia de tomá-los como adversários a abater. Por isso, seria relevante a leitura do livro organizado por Saviani e Duarte ${ }^{18}$, no qual, em profundidade, debatem e qualificam o teor da crítica. justamente ao mais importante intelectual marxista da área, por sua incomparável produção teórica e pela clareza do lado em que situa sua militância na luta de classe? E qual seria, agora, a intenção de Tumolo em publicar um texto requentando os mesmo argumentos de $2003^{13}$, justamente na coletânea "Caminhos da politecnia: 30 anos da Escola Politécnica Joaquim Venâncio" (2016), juntando agora Saviani e Frigotto?

Registra-se que o primeiro foi quem dominantemente deu a concepção teórica e política da Escola Politécnica na sua origem e o segundo, quem aceitou a interpelação feita pelos então mestrandos, jovens profissionais da Fundação Oswaldo Cruz - André Malhão, Bianca Antunes Cortez e Julio Cesar França Lima -, para ajudá-los na formulação da proposta e, ao longo desses trinta anos, nunca negou a sua frequente colaboração. Mais estranho é que o texto apareça na seção cujo título é: "Debates atuais para uma educação emancipadora". O que se poderia interpretar é que Saviani e Frigotto já não são atuais e, além disso, suas contribuições não concorrem para uma educação emancipadora e, consequentemente, há necessidade de a escola ter novos referenciais ${ }^{(f)}$. 


\section{Referências}

1. Marx K, Engels F. A ideologia alemã: Feuerbach - a contraposição entre as cosmovisões materialista e idealista. São Paulo: Martin Claret; 2005.

2. Marx K. O capital. São Paulo: Abril Cultural; 1983.

3. Saviani D. A relação trabalho e educação: fundamentos ontológicos e históricos. Rev Bras Educ. 2007; 12(34):152-80.

4. Marx K, Engels F. La ideologia alemana. Montevideo: Pueblos Unidos; 1974.

5. Engels F. Revista de teoria e política marxista [Internet]. São Paulo: Edições Iskra. 2014 [citado 04 Jul 2016]; Disponível em: http://edicoesiskra.blogspot.com.br/.

6. Saviani D. Educação em diálogo. Campinas: Autores Associados; 2011. p. 119-44.

7. Saviani D. Educação em diálogo. Campinas: Autores Associados; 2011. p. 217-30.

8. Saviani D. Sobre a concepção de politecnia. Rio de Janeiro: EPSJV/Fiocruz; 1989.

9. Saviani D. Choque teórico da politecnia. Trab Educ Saude. 2003; 1(1):131-52.

10. Barata-Moura J. Totalidade e contradição. Acerca da dialética. Lisboa: Editorial Avante; 2012.

11. Saviani D. Escola e democracia. Campinas: Autores Associados; 2008. p. 65-74.

12. Lessa S. Trabalho e proletariado no capitalismo contemporâneo. São Paulo: Cortez; 2007.

13. Tumolo PS. O significado do trabalho no capitalismo e o trabalho como princípio educativo: ensaio de análise crítica. Trab Necessario. 2003; 1(1):1-16.

14. Frigotto GA. Polissemia da categoria trabalho e a batalha das ideias nas sociedades de classe. Rev Bras Educ. 2009; 14(40):168-94.

15. Negro AL, Silva $S$, organizadores. As peculiaridades dos ingleses e outros artigos de $E$. P. Thompson. Campinas: Editora da Unicamp; 2007.

16. Tumolo PS. Bases teórico-políticas para a discussão da educação da perspectiva da classe trabalhadora. In: Escola Politécnica de Saúde Joaquim Venâncio, organizadora. Caminhos da politecnia: 30 anos da Escola Politécnica de Saúde Joaquim Venâncio. Rio de Janeiro: EPSJV; 2016. p. 406-61.

17. Lazarini AQ. A relação entre capital e educação escolar na obra de Dermeval Savani [tese]. Florianópolis (SC): Universidade Federal de Santa Catarina; 2010.

18. Saviani D, Duarte N, organizadores. Pedagogia histórico-crítica e luta de classe na educação escolar. Campinas: Autores Associados; 2012.

19. Oliveira F de. O elo perdido: classe e identidade de classe. São Paulo: Brasiliense; 1987.

20. Saviani D. Questões para Dermeval Saviani [entrevista a Bassani E, Caliari R, Dalvi MA, Simões V, Zanin L]. Pró-Discente Cad Prod Acad-Cient Progr Pós-Grad. Educação [Internet]. 2009; [citado 04 Jul 2016]. 15(2):110-6. Disponível em: http://periodicos.ufes. br/PRODISCENTE/article/download/5737/4185. 
Frigotto G. Dermeval Saviani y la centralidad ontológica del trabajo en la formación del "hombre nuevo", artífice de la sociedad socialista. Interface (Botucatu). 2017; 21(62):509-19.

Este texto deja explícita la centralidad ontológica del trabajo en el conjunto de la obra del filósofo y educador Dermeval Saviani. La concepción materialista de la historia, el método dialéctico de comprensión de la realidad humana y el sentido de la acción política se fundamentan en la actividad vital del trabajo y en cómo este se define en las relaciones sociales de producción material de la existencia en el transcurso del tiempo. Al final, se analiza la visión exegética y heurística de "nuevas" críticas del pensamiento del autor.

Palabras clave: Método dialéctico. Trabajo. Educación. Política. Heurística. 
